\title{
S Peertechz
}

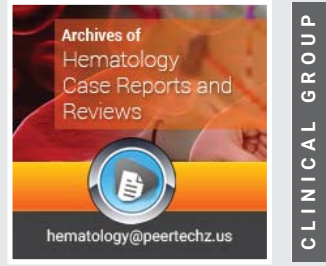

\section{Combined treatment with}

vemurafenib and cobimetinib

\section{in Langerhans cell}

\section{histiocytosis and Erdheim-}

Chester disease overlap

\section{syndrome: A case Report}

\section{Hidalgo-Soto Marta ${ }^{1 *}$, Poza-Santaella María ${ }^{2}$, Pita-Suárez Daniel $^{3}$, Calbacho-Robles María², Pina-Sánchez José2, González-Medina José ${ }^{4}$ and Baumann Tycho Stephan ${ }^{2}$}

${ }^{1}$ Consultant Hematologist, Clinical Trial Unit, Department of Hematology, Vall d'Hebron Institute of Oncology, University of Valladolid, Spain

${ }^{2}$ Department of Hematology, Hospital Universitario 12 de Octubre, Madrid, Spain

${ }^{3}$ Department of Pathology, Hospital Universitario 12 de Octubre, Madrid, Spain

${ }^{4}$ Department of Hematology, Hospital Fundación Jiménez Díaz, Madrid, Spain

Received: 04 January, 2022

Accepted: 19 January, 2022

Published: 20 January, 2022

*Corresponding author: Hidalgo-Soto Marta,

Consultant Hematologist, Clinical Trial Unit, Department of Hematology, Vall d'Hebron Institute of Oncology, University of Valladolid, Spain, Tel: +34 6996965 45; Fax: 9348940 64; Email: martahiso2@outlook.com

\section{ORCID: https://orcid.org/0000-0003-0910-6752}

Copyright License: (c) 2022 Marta HS, et al. This is an open-access article distributed under the terms of the Creative Commons Attribution License, which permits unrestricted use, distribution, and reproduction in any medium, provided the original author and source are credited.

Keywords: Mixed histiocytosis; Erdheim-chester disease; Langerhans cell histiocytosis; Cobimetinib; Vemurafenib

https://www.peertechzpublications.com

\section{Check for updates}

\section{Abstract}

Histiocytoses are clonal disorders diseases derived from the monocyte-macrophage lineage. The Erdheim-Chester Disease (ECD) and Langerhans Cell Histiocytosis (LCH) may occur in association with overlapping clinical, histopathological and molecular features, harboring somatic MAP2K1 mutations in more than $50 \%$ of patients. BRAF and MEK inhibitors have shown to be efficacious in ECD and $\mathrm{LCH}$, including responses in patients with CNS involvement.

This case report describes a 59-year-old woman who presented with vemurafenib-refractory ECD/LCH overlap syndrome treated with vemurafenib/cobimetinib dual therapy, with rapidly progressing neurological involvement after its initiation.

Although targeted therapy plays a crucial role in the treatment of histiocytosis, only anecdotal clinical cases treated with dual therapy have been reported in ECD or $\mathrm{LCH}$ and collaborative trials are needed to improve outcomes.

\section{Background}

Histiocytic disorders are a heterogeneous group of rare progressive and multisystemic diseases, which can be classified as either Langerhans Cell Histiocytosis (LCH) or non-LCHs according to clinical, anatomical and mutational findings.

Erdheim-Chester Disease (ECD) is a non-LHC that belongs to the Langerhans ' $\mathrm{L}$ ' group together with $\mathrm{LCH}$. Both derive from the monocyte-macrophage lineage with recurrent clonal mutations, such as BRAFV600E in early, multipotent progenitor cells $[1,2]$. ECD is characterized by xanthogranulomatous infiltration produced by Touton-like giant cells, lymphocytic aggregates and CD68/CD163 positive-CD1a/S100 negative foamy histiocytes $[3,4]$. Conversely, LCH expresses the histiocyte markers CD1a, S100, CD207 (langerin) and CD68low [1].

The existence of a possible common progenitor for ECD and LCD may explain the fact that almost $20 \%$ of ECD cases were previously diagnosed as LCH $[2,3]$. ECD/LCH overlap has been 
recognized, however, its prevalence is unknown. Hervier et al emphasized the high frequency of mixed histiocytosis $(\mathrm{MH})$ in a series of 23 cases [5].

The identification of the BRAFV600E mutation in ECD/ LCH (2010) has been reported in $69 \%$ of patients with $\mathrm{MH}$ compared to $57 \%$ and $54 \%$ in isolated LCH and ECD, respectively [2,3-6]. In 2012, 3 patients with refractory ECD ( 2 of them had LCH involvement) were treated with vemurafenib, with clinical and radiological improvement after one month of treatment [7]. Five years later, vemurafenib achieved FDA approval for the treatment of ECD based on the results of the VE-BASKET [8] and the LOVE trial [9].

In addition, the improved knowledge about the RAS-RAFMEK-ERK pathway has been gained by the characterization of additional, activating mutations, such as ARAF, RAF1, NRAS, KRAS, and MEK1/2. Interestingly, MEK inhibitors have shown clinical efficacy regardless of genotype [11]. Recently, promising outcomes have been reported in $3 \mathrm{ECD}$ patients with BRAFV600E mutation and central nervous system (CNS) involvement with vemurafenib/cobimetinib combined therapy after progression on single-agent vemurafenib. Two of them achieved complete metabolic remissions evaluated by imaging techniques and all of them showed neurological improvement [12].

Herein, we report on vemurafenib/cobimetinib combination regimen in a BRAF-mutant vemurafenib-refractory $\mathrm{MH}$ patient with multisystemic involvement and progressive neurodegenerative symptoms.

\section{Case report}

A 59 years-old woman with a 1-year history of bone pain (especially back pain, lower limbs and shoulder), paresthesia of lower limbs, constitutional symptoms, hepatosplenomegaly, bilateral exophthalmos and xanthelasma palpebrarum. Technetium-99m (99mTc) bone scan showed increased uptake in the diaphyses and metaphyses sparing the epiphyses of the femur and tibia, while computed tomography scan revealed perinephric soft tissue infiltrate and sheathing of the whole thoracoabdominal aorta. (18F)-fluorodeoxyglucose (FDG)-PET (FDG-PET)-imaging revealed moderate uptake in visceral and bone lesions... Also, right atrial and ventricle pseudotumor was observed by magnetic resonance imaging (MRI) (Figure 1).

Bone biopsies on target lesions revealed the existence of the ECD/LCH overlap syndrome, showing an infiltrate by CD68-CD1a- foamy histiocytes and histological lesions where CD1a, Langerin and S100-positive Langerhans cells were found (Figure 2).

Initially, the BRAFV60oE mutation was not detected, probably due to the low tumor load of the first sample, so an additional bone biopsy was performed in which the BRAFV600E activating mutation was detected. Whole-exome sequencing also identified mutations in CSDE1 (c.35G>A; p.Gly12As; Variant allele frequency [VAF]: $8.42 \%$ ) and KRAS (c.436G $>A$; p.Ala146Th; VAF: 4.56\%).

Induction chemotherapy with weekly vinblastine $(6 \mathrm{mg} /$ $\mathrm{m} 2$ ) and prednisolone $40 \mathrm{mg} / \mathrm{m} 2$ for 6 weeks was started in
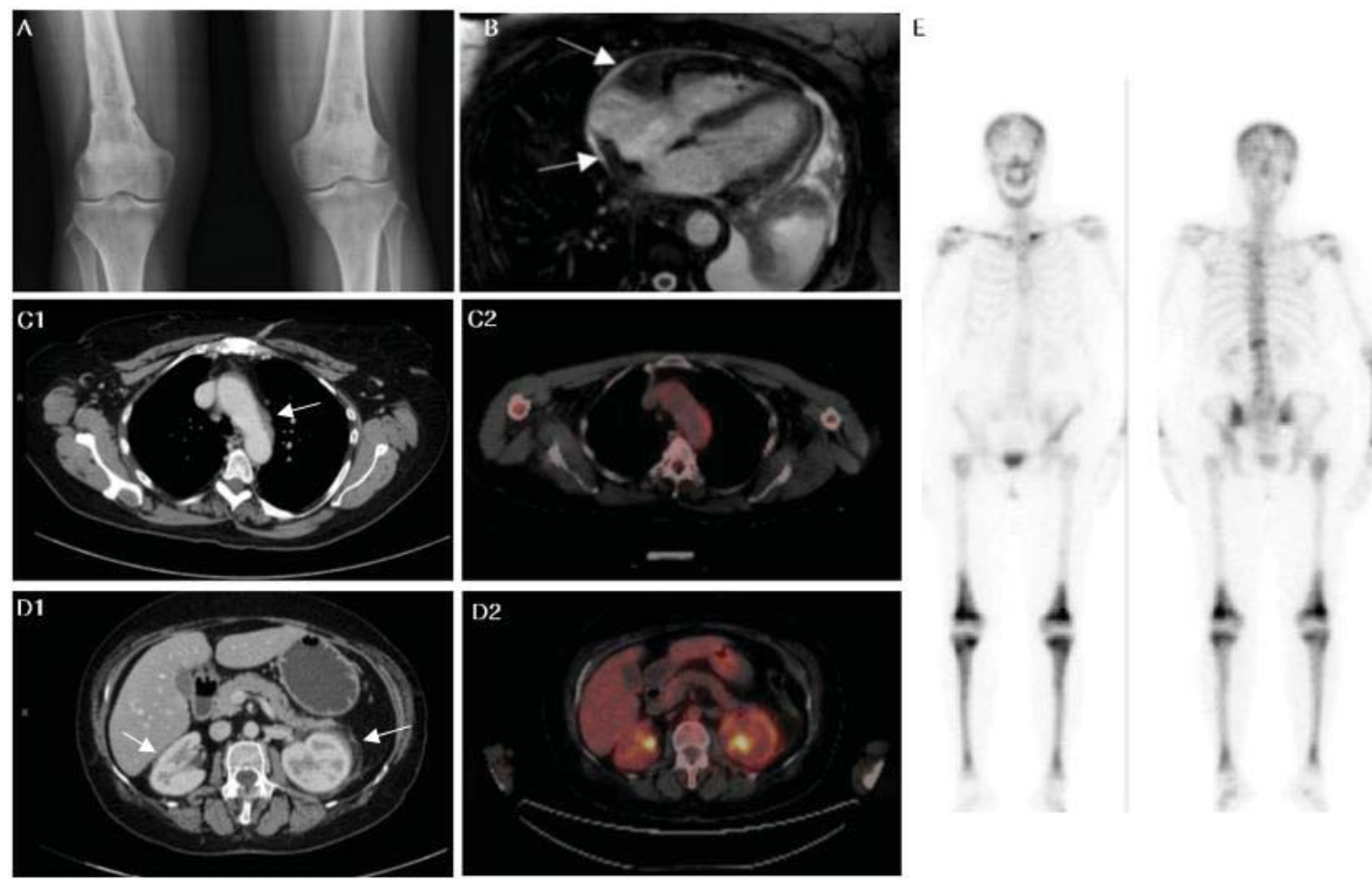

Figure 1: Radiographic findings of ECD/ LCH. Bone $x$-ray shows lytic lesions and bone erosions in the distal extremity of both femurs. (B) Right atrial and ventricle mass is demonstrated in MRI. (C1) Axial CT scan shows the sheathing of the whole thoracic aorta called "coated aorta". (C2) FDG-avid peri-aortic soft tissue in PET scan (SUVmax 4,32). (D1) Perirenal fat infiltration is referred to as a "hairy kidney". (D2) Increased FDG-glucose uptake in perirenal soft tissue (SUVmax 6,49 on the left side; 4,86 on the right side). (E) ${ }^{99 m} \mathrm{Tc}$ imaging demonstrating increased uptake in the distal ends of the lower limbs. 


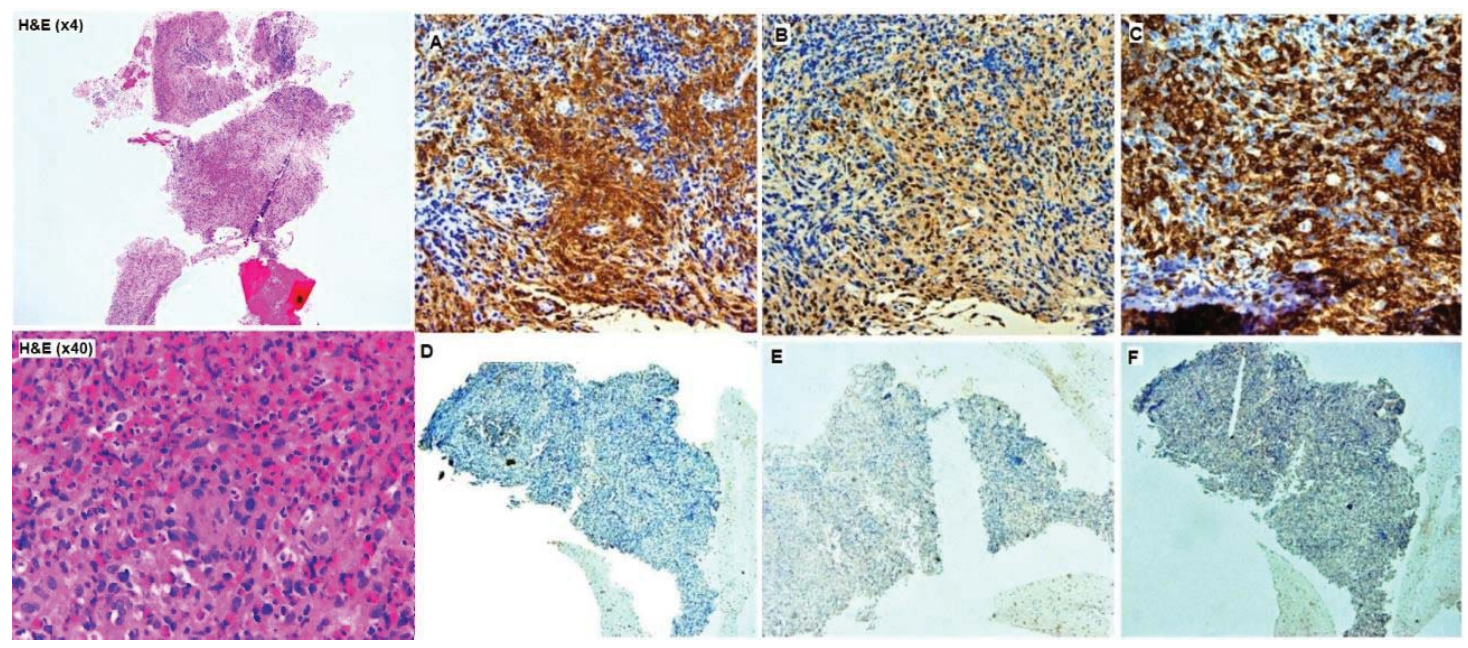

Figure 2: Pathologic and immunohistochemical findings of mixed histiocytosis in the bone biopsy. Haematoxylin-eosin stain (H\&E, x4, and x40) images show fibroconnective tissue and fragments of bone material infiltrated by mixed inflammatory cellularity: histiocytes, abundant eosinophils, and polymorphonuclear cells. Top: Histological features of Langerhans cell histiocytosis. (A) Immunoreactivity of CD1a expression by Langerhans cells ( $\times 20)$. (B) Expression of the histiocyte marker S100 (x20). (C) CD207 (langerin)-positive cells (x20). Bottom: Tissue biopsy showing histiocytes with non-Langerhans features. Immunohistochemical analysis shows CD1a-negative (D,x4), S100negative $(E, \times 4)$ and $C D 207$-negative $(F, x 4)$ foamy histiocytes.

October 2019. Subsequently, in maintenance treatment, daily oral mercaptopurine (6-MP) 40mg/m2 was associated with vinblastine every 3 weeks. Prednisolone was tapered weekly. MRI and FDG-PET were performed to assess tumor burden.

After 10 cycles of treatment, a partial response was observed by FDG-PET. However, after 1-year of treatment, new-onset neurological symptoms characterized primarily by cerebellar dysfunction and radiographic lung involvement were detected. Brain MRI at this time demonstrated periventricular white matter lesions that were hyperintense on T2/FLAIR images and global brain atrophy. Cerebrospinal Fluid (CSF) protein was slightly elevated $(1.31 \mathrm{~g} / \mathrm{l})$ and Polymerase Chain Reaction (PCR) for JC-virus Desoxyribonucleic Acid (DNA) was negative.

Due to disease progression, vemurafenib 960mg PO twice daily was started as a single agent. Photosensitivity was a bothersome complication of the treatment; therefore, vemurafenib dose had to be lowered to 480mg PO twice daily. After one month of treatment, a partial response with a generalized decrease in the uptake of thoracic and perirenal soft tissue lesions was achieved. The patient experienced a progressive worsening of neurological symptoms. This fact was determinant to initiate third-line therapy based on dual BRAF/MEK inhibition in order to achieve a greater depth of response including the CNS.

Cobimetinib was associated at a starting dose of $60 \mathrm{mg}$ daily for 21 days of each 28-day cycle. However, after 2 cycles of combined therapy, the patient was admitted to our hospital with rapidly progressive neurological deterioration presenting delirium, dysarthria, headache and worsening ataxia, rendering her bed-bound.

Intriguingly, the MRI at this time showed improvement of white matter lesions (Figure 3) and stable disease was seen on FDG-PET scan with a slight decrease in the inflammatory activity of visceral lesions and soft tissue tissues, although an increase in bone uptake was observed at multiple levels.
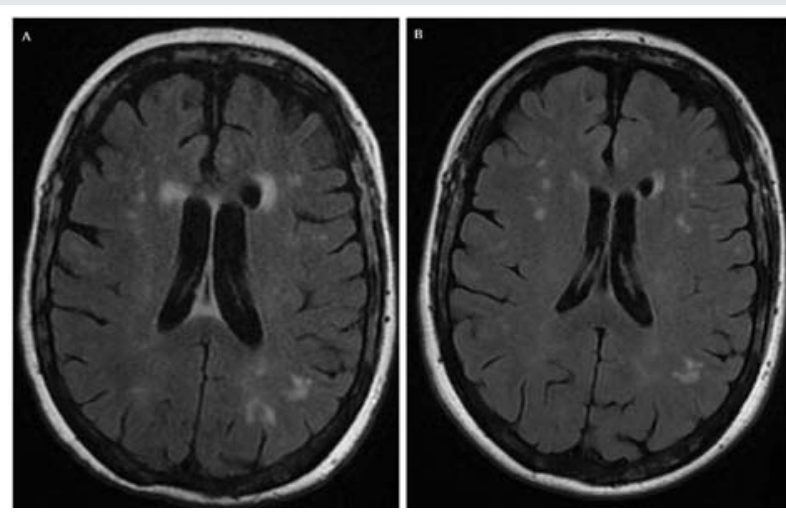

Figure 3: Brain magnetic resonance imaging. A: Before vemurafenib/Cobimetinib dual therapy. MRI shows periventricular white matter hyperintensities and global brain atrophy on T2/FLAIR images. B: After vemurafenib/Cobimetinib dual therapy, MRI shows radiological improvement of the bihemispheric white matter lesions.

Vemurafenib and cobimetinib therapy was discontinued and corticosteroid therapy was started (initial dose of $8 \mathrm{mg}$ of dexamethasone IV followed by $4 \mathrm{mg}$ IV daily), leading to a transient improvement in speech fluency, swallowing and fine motor skills. In agreement with the family, treatment was not resumed and palliative care was started.

\section{Disscusion}

Mixed histiocytosis or ECD/ LCH overlap syndrome is believed to derive from activating mutations targeting the BRAF/ MPAK pathway of early ancestor cells of the monocyte-macrophage system. While recognized as an entity in the revised WHO class (2016), its diagnosis is challenging and less than 100 adult patients have been reported.

Our patient with $\mathrm{MH}$ displayed characteristics very similar to those of cases with isolated ECD. In this disease, skeletal involvement is practically invariably present (95\%), being the most affected bones femur and tibia, with symmetric diaphyseal osteosclerosis with avid FDG uptake at bone scan 
$[3,6,13,14]$. About $50 \%$ of patients may feature extra-skeletal manifestations, such as constitutional symptoms, retroperitoneal involvement leading to obstructive acute kidney injury, skin manifestations, neurological alterations, diabetes insipidus and pulmonary or cardiac manifestations secondary to tumor infiltration $[3,4,14,15]$.

Determination of mutations that produce constitutive activation of the mitogen-activated protein kinase (MAPK) pathway is a standard of care. The high prevalence of BRAFV600E variant confirms the clonal nature of the disease $[1,5,16]$. This mutation was shown to occur with a similar frequency ( $>50 \%$ of patients) in non-Langerhans cell histiocytosis and histiocytosis $X[1,6,10]$, correlating with a more severe disease development involving the atrium or the CNS $[2,3,13]$.

This finding was key for assessing the effectiveness of targeted therapies against BRAF in 2012 in ECD, with excellent results being reported in small case series [7].

A similar response was obtained in patients from the LOVE trial (cohort of 54 patients with ECD including $20 \mathrm{MH}$ patients) [9]. The results of this study show a high response rate of $91 \%$ in BRAFV600E-mutated ECD. Later, excellent outcomes were obtained in 26 patients from the VE-BASKET trial (no $\mathrm{MH}$ patients were included). All patients evaluated by FDG-PET/ CT achieved metabolic response with 2-year progression-free survival (PFS) of $86 \%$ at 2-year of follow-up (95\% CI, $72 \%$ $100 \%$ ) and 2-year overall survival (OS) of $96 \%$ (95\% CI, $87 \%$ $-100 \%)[8]$.

On the other hand, synergy is expected between MEK $1 / 2$ and BRAF-inhibitors, as they interfere in the same pathway at different levels. However, only anecdotal clinical cases treated with dual therapy have been reported with favorable responses $[12,17,18]$

Here, we present to the best of our knowledge the first report on the combination of vemurafenib and cobimetinib in an $\mathrm{MH}$ patient harboring the BRAFV600E mutation with rapidly progressing neurological symptoms after initiation of dual therapy. Though, MRI showed the partial response of T2/ FLAIR-hyperintense lesions without restricted diffusion. This clinical deterioration led to treatment discontinuation, with a temporarily neurological improvement. Previously, adverse events with BRAF/MEK inhibitors such as acute encephalopathy, have been reported in melanoma cases. Engel et al. reported a suspected case of reversible posterior encephalopathy after vemurafenib and cobimetinib initiation in metastasic melanoma, identifying three more cases of acute-onset encephalopathy after combined treatment with BRAF and MEK inhibitors [19]. In ECD patients, Saunders et al. reported more serious adverse effects in those ECD patients who received dual therapies [20].

In conclusion, the ECD/LCH overlap syndrome shares the same pathogenetic link between ECD and LCH, being ECD the major component of the disease. The discovery of activating mutations in the MAPK/ERK pathway, has led researchers to investigate targeted immune-modulatory therapies. However, questions remain regarding efficacy, optimal combination and duration of treatment. Multinational efforts are needed in this rare entity to address these questions within clinical trials.

\section{Acknowledgment}

Informed consent was obtained from the patient for being included in the study.

\section{Authors' contributions}

M.H.S. wrote the first draft of the manuscript and was involved in the patient's care; J.S.P and M.C.R were involved in the patient's care; M.P.S. and J.G.M. carried out a bibliographic review of the literature. D.S.P provided the histological images. T.S.B. revised and added content to the manuscript. All authors read and approved the final manuscript.

\section{References}

1. Emile JF, Abla O, Fraitag S, Horne A, Haroche J, et al. (2016) Revised classification of histiocytoses and neoplasms of the macrophage-dendritic cell lineages. Blood 127: 2672-2681. Link: https://bit.ly/3rsiHz0

2. Badalian-Very G (2014) A common progenitor cell in LCH and ECD. Blood 124 : 991-992. Link: https://bit.ly/3lbayWt

3. Haroche J, Cohen-Aubart F, Amoura Z (2020) Erdheim-Chester disease. Blood 135: 1311-1318. Link: https://bit.ly/34R494p

4. Haroche J, Amoura Z, Dion E, Wechsler B, Costedoat-Chalumeau N, et al. (2004) Cardiovascular involvement, an overlooked feature of Erdheim-Chester disease: report of 6 new cases and a literature review. Medicine (Baltimore) 83: 371-392. Link: https://bit.ly/3fvYB1n

5. Hervier B, Haroche J, Arnaud L, Charlotte F, Donadieu J, et al (2014). Association of both Langerhans cell histiocytosis and Erdheim-Chester disease linked to the BRAFV600E mutation. Blood 124: 1119-1126. Link: https://bit.ly/34R8gNP

6. Cives M, Simone V, Rizzo FM, Dicuonzo F, Cristallo Lacalamita M, et al. (2015) Erdheim-Chester disease: a systematic review. Crit Rev Oncol Hematol 95 1-11. Link: https://bit.ly/3KfzspP

7. Haroche J, Cohen-Aubart F, Emile JF, Arnaud L, Maksud P, et al. (2013) Dramatic efficacy of vemurafenib in both multisystemic and refractory Erdheim-Chester disease and Langerhans cell histiocytosis harboring the BRAF V600E mutation. Blood 121: 1495-1500. Link: https://bit.ly/3tyWm5z

8. Diamond EL, Subbiah V, Lockhart AC, Blay JY, Puzanov I, et al. (2018) Vemurafenib for BRAF V600-Mutant Erdheim-Chester Disease and Langerhans Cell Histiocytosis: Analysis of Data from the Histology-Independent, Phase 2, Open-label VE-BASKET Study. JAMA Oncol 4: 384-388.Link: https://bit.ly/33Jpegv

9. Cohen Aubart F, Emile JF, Carrat F, Charlotte F, Benameur N, et al. (2017) Targeted therapies in 54 patients with Erdheim-Chester disease, including follow-up after interruption (the LOVE study). Blood 130: 1377-1380. Link: https://bit.ly/3GGKBhh

10. Emile JF, Diamond EL, Hélias-Rodzewicz Z, Cohen-Aubart F, Charlotte F, et al. (2014) Recurrent RAS and PIK3CA mutations in Erdheim-Chester disease. Blood 124: 3016-3019. Link: https://bit.ly/355A01x

11. Diamond EL, Durham BH, Ulaner GA, Drill E, Buthorn J, et al. (2019) Efficacy of MEK inhibition in patients with histiocytic neoplasms. Nature 567: 521-524. Link: https://go.nature.com/3GJDF30

12. Mazor RD, Weissman R, Luckman J, Domachevsky L, Diamond EL, et al. (2020) Dual BRAF/MEK blockade restores CNS responses in BRAF-mutant ErdheimChester disease patients following BRAF inhibitor monotherapy. Neurooncol Adv 2: vdaa024. Link: https://bit.ly/3tBndOx 
13. Cohen-Aubart F, Emile JF, Carrat F, Helias-Rodzewicz Z, et al. (2018) Phenotypes and survival in Erdheim-Chester disease: results from a 165-patient cohort. Am J Hematol 93: E114-E117. Link: https://bit.ly/3fFUTIX

14. Cavalli G, Guglielmi B, Berti A, Campochiaro C, Sabbadini MG, et al. (2013) The multifaceted clinical presentations and manifestations of Erdheim-Chester disease: comprehensive review of the literature and of 10 new cases. Ann Rheum Dis 72: 1691-1695. Link: https://bit.ly/3fAzLOr

15. D, Cappelli C, Mizzoni F, Noto C, Toscano D, et al. (2004) Erdheim-Chester disease: a non-Langerhans cell histiocytosis. A clinical-case and review of the literature. Clin Ter 155: 205-208. Link: https://bit.ly/3tCkMuX

16. Badalian-Very G, Vergilio JA, Degar BA, MacConaill LE, Brandner B et al. (2010) Recurrent BRAF mutations in Langerhans cell histiocytosis. Blood 116: 1919-1923. Link: https://bit.ly/3tBnjFT
17. Estrada-Veras Jl, O’Brien KJ, Boyd LC, Dave RH, Durham B, et al. (2017) The clinical spectrum of Erdheim-Chester disease: an observational cohort study. Blood Adv 1: 357-366. Link: https://bit.ly/3nGR2t9

18. Al Bayati A, Plate T, Al Bayati M, Yan Y, Lavi ES, et al. (2018) Dabrafenib and trametinib treatment for Erdheim-Chester disease with brain stem involvement. Mayo Clin Proc Innov Qual Outcomes 2: 303-308. Link: https://bit.ly/3GIUtXS

19. Engel S, Luessi F, Henning B, Bittner S, Loquai C, et al. (2019) Vemurafenib and cobimetinib combination therapy for BRAFV600E-mutated melanoma favors posterior reversible encephalopathy syndrome. Ann Oncol 30: 1014-1016. Link: https://bit.ly/3Imsv4H

20. Saunders IM, Goodman AM, Kurzrock R (2020) Real-World Toxicity Experience with BRAF/MEK Inhibitors in Patients with Erdheim-Chester Disease Oncologist 25: e386-e390. Link: https://bit.ly/3Aczom1
Discover a bigger Impact and Visibility of your article publication with Peertechz Publications

\section{Highlights}

* Signatory publisher of ORCID

* Signatory Publisher of DORA (San Francisco Declaration on Research Assessment)

* Articles archived in worlds' renowned service providers such as Portico, CNKI, AGRIS, TDNet, Base (Bielefeld University Library), CrossRef, Scilit, J-Gate etc.

* Journals indexed in ICMJE, SHERPA/ROMEO, Google Scholar etc.

* OAI-PMH (Open Archives Initiative Protocol for Metadata Harvesting)

* Dedicated Editorial Board for every journal

* Accurate and rapid peer-review process

* Increased citations of published articles through promotions

- Reduced timeline for article publication

Submit your articles and experience a new surge in publication services (https://www.peertechz.com/submission).

Peertechz journals wishes everlasting success in your every endeavours. 